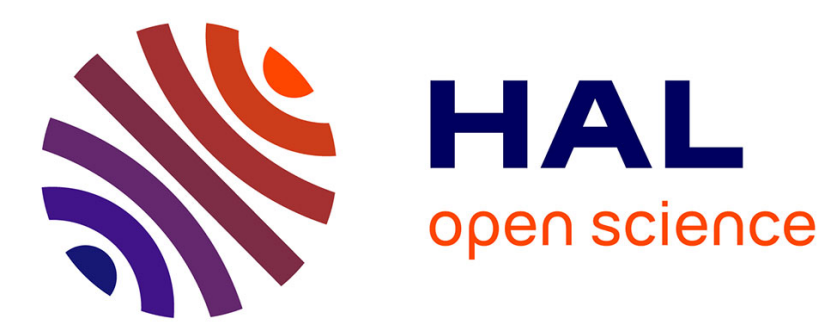

\title{
Thermodynamic analysis of the short-range clustering in III V solid solutions
}

\author{
A. Marbeuf, J.C. Guillaume
}

\section{To cite this version:}

A. Marbeuf, J.C. Guillaume. Thermodynamic analysis of the short-range clustering in III V solid solutions. Revue de Physique Appliquée, 1984, 19 (4), pp.311-318. 10.1051/rphysap:01984001904031100 . jpa-00245198

\section{HAL Id: jpa-00245198 https://hal.science/jpa-00245198}

Submitted on 1 Jan 1984

HAL is a multi-disciplinary open access archive for the deposit and dissemination of scientific research documents, whether they are published or not. The documents may come from teaching and research institutions in France or abroad, or from public or private research centers.
L'archive ouverte pluridisciplinaire HAL, est destinée au dépôt et à la diffusion de documents scientifiques de niveau recherche, publiés ou non, émanant des établissements d'enseignement et de recherche français ou étrangers, des laboratoires publics ou privés. 


\title{
Thermodynamic analysis of the short-range clustering in III V solid solutions
}

\author{
A. Marbeuf $\left({ }^{*}\right)$ and J. C. Guillaume $\left({ }^{* *}\right)$ \\ (*) CNRS, Laboratoire de Physique des Solides, 1, place A. Briand, 92195 Meudon, France \\ (**) CNRS, Laboratoire de Physique du Solide et de l'Energie solaire, \\ rue B. Grégory, Sophia Antipolis, 06560 Valbonne, France
}

(Reçu le 25 juillet 1983, révisé et accepté le 17 janvier 1984)

\begin{abstract}
Résumé. - Une généralisation du formalisme « D.L.P. » de Stringfellow prenant en compte la tendance aux amas a été appliquée à la fois aux alliages pseudobinaires, pseudoternaires et pseudoquaternaires III V. Pour les alliages où les sous-réseaux sont à deux sites, cette tendance est traduite, pour chaque sous-réseau de la "blende de zinc " par un paramètre d'ordre à courte distance $\alpha_{i-j}$ positif, dépendant de la température et de la composition. Les valeurs obtenues pour $\alpha_{G a-I n}$ démontrent que, pour la série $\operatorname{Ga}_{x} \operatorname{In}_{1-x} X(X=S b, A s, P)$, la tendance s'accroît lorsque l'on passe de $\operatorname{Sb}\left(\alpha_{\mathrm{Ga}-\operatorname{In}\left(1 / 2,700^{\circ} \mathrm{C}\right)}=0,04\right)$ à $\mathrm{P}\left(\alpha_{\mathrm{Ga}-\operatorname{In}\left(1 / 2,7^{\circ} 0^{\circ} \mathrm{C}\right)}=0,08\right)$, tandis que InAs $\mathbf{P}_{1-y}$, et dans une moindre mesure $\mathrm{GaAs}_{y} \mathrm{P}_{1-y}$, comportent une répartition aléatoire des atomes As et $\mathrm{P}$. Pour un pseudoquaternaire, le modèle prévoit une variation linéaire de $\alpha_{i-j}$ avec la composition de l'autre sous-réseau. Les lacunes de miscibilité calculées sont en accord avec les résultats expérimentaux connus pour $\mathrm{Ga}_{x} \operatorname{In}_{1-x} \mathbf{P}$ et $\mathrm{Ga}_{x} \mathrm{In}_{1-x} \mathrm{As}_{y} \mathbf{P}_{1-y}$ : les températures critiques sont respectivement $750^{\circ} \mathrm{C}$ et $880^{\circ} \mathrm{C}$. Par contre le modèle ne peut expliquer une lacune de miscibilité à forme asymétrique comme dans le cas de $\mathrm{GaAs}_{y} \mathrm{Sb}_{1-y}$ si l'entropie d'excès se réduit à une entropie de configuration.
\end{abstract}

\begin{abstract}
An extension of the " D.L.P. " theory of Stringfellow taking clustering into account has been applied both to pseudobinary, pseudoternary and pseudoquaternary III V alloys. For alloys with two sites sublattices, this clustering tendency is introduced in each sublattice of the zinc blende through a positive short-range order parameter $\alpha_{i-j}$ depending on temperature and composition. It is shown that clustering increases in $\operatorname{the} \mathrm{Ga}_{x} \mathrm{In}_{1-x} \mathrm{X}$ serie $(X=S b, A s, P)$ from the antimonide $\left(\alpha_{\mathrm{Ga}-\operatorname{In}\left(1 / 2,700^{\circ} \mathrm{C}\right)}=0.04\right)$ to the phosphide $\left(\alpha_{\mathrm{Ga}-\operatorname{In}\left(1 / 2,700^{\circ} \mathrm{C}\right)}=0.08\right)$ whereas $\mathrm{GaAs}_{y} \mathrm{P}_{1-y}$ and mainly InAs $\mathbf{P}_{1-y}$ have quite random As-P distribution. For pseudoquaternaries the model predicts a linear variation of $\alpha_{i-j}$ versus the composition of the other sublattice. The calculated miscibility gaps are in good agreement with known experimental results for $\mathrm{Ga}_{x} \mathrm{In}_{1-x} \mathrm{P}$ and $\mathrm{Ga}_{x} \mathrm{In}_{1-x} \mathrm{As}_{y} \mathrm{P}_{1-y}$ (the critical temperatures are respectively 750 and $880^{\circ} \mathrm{C}$ ), whereas the model does not explain an asymmetrical shape of miscibility gap as in the case of $\mathrm{GaAs}_{y} \mathrm{Sb}_{1-y}$ if the excess entropy reduces only to a configurational one.
\end{abstract}

\section{Introduction.}

The III V multicomponent semiconductors which are studied and used in optoelectronic devices or solar cells can be prepared by one of the three following epitaxy methods : liquid phase epitaxy (L.P.E.), vapour phase epitaxy (V.P.E.), molecular beam epitaxy (M.B.E.). Only the first two are nearly equilibrium crystal growth technics. Phase diagrams, calculated from the limiting binary systems, are useful for predicting experimental conditions of ternary or quaternary crystal growth. A strain energy term associated with lattice mismatch may be introduced [1-3] in the Gibbs energy of the alloy. On the other hand, partial shortrange clustering of like atoms in the zinc-blende sublattices allows better understanding of III V phase diagrams : the authors [3] have shown the peculiar importance of this clustering tendency for the shape and the locus of miscibility gaps in three or four component systems. Quite recently, Yamazaki et al. [4] have established a thermodynamic model of pseudobinary solid solutions taking into account the clustering tendency of atoms in the substituted sublattice. But their values of short-range order parameter (S.R.O.P.) lead to excess thermodynamic functions uncompatible with the phase diagrams : in the $\mathrm{Ga}_{x} \operatorname{In}_{1-x} \mathrm{P}$ case, for the medium composition where clustering effect is maximal, these workers found 0.32 for the Ga-In S.R.O.P., whereas Brühl et al. [5] had deduced 0.13 from diffuse X Ray scatter- 
ing. Besides, the Ga-In S.R.O.P. calculated by Yamazaki et al. for the $\mathrm{Ga}_{x} \mathrm{In}_{1-x} \mathrm{X}$ serie $(\mathrm{X}=\mathrm{P}, \mathrm{As}, \mathrm{Sb})$ are higher than the Al-In ones for the analogous $\mathrm{Al}_{x} \mathrm{In}_{1-x} \mathrm{X}$ serie, whereas the opposite effect based on electronegativity considerations is expected. Ultimately, enthalpies of mixing related to the S.R.O.P. $(\sim 0.35)$ have the same values for the $\mathrm{GaAs}_{y} \mathrm{Sb}_{1-y}$ and the $\mathrm{Ga}_{x} \operatorname{In}_{1-x} \mathrm{P}$ alloys, that which would lead to similar miscibility gap in contradiction with experiments. The same quasi-chemical treatment of Jones et al. [6] gives a more realistic degree of clustering but too low values of critical temperature alloys.

Onabe has established an improved theory based on the pair approximation which is available for $A_{x} B_{1-x} C_{y} D_{1-y}$ pseudoquaternary solid solution [7]. Thermodynamic parameters however which allow to calculate enthalpy and entropy of mixing of the solid are deduced from quaternay liquid $\rightleftarrows$ pseudoquaternary alloy equilibrium. Consequently, this model depends on the thermodynamic data of the liquid phase. As observed by Onabe [7], the theory does not take into account the quasi-chemical nature of the AC, $\mathrm{AD}, \mathrm{BC}$ and $\mathrm{BD}$ pair distribution and is reduced to quasi-regular model (random distribution of atoms) in the limiting pseudobinary solid solutions, $\mathrm{A}_{x} \mathrm{~B}_{1-x} \mathrm{C}$, $\mathrm{A}_{x} \mathrm{~B}_{1-x} \mathrm{D}, \mathrm{AC}_{y} \mathrm{D}_{1-y}$ and $\mathrm{BC}_{y} \mathrm{D}_{1-y}$.

Finally, the important case of pseudoternary alloys $\left(A_{x} B_{y} C_{1-x-y} D\right.$ or $\left.A_{B} C_{y} D_{1-x-y}\right)$ where mixing occurs in one sublattice with three different elements has never been taken into account.

sis encies, a new thermodynamic model is proposed allowing the calculation of the S.R.O.P. and the mixing functions of a pseudobinary alloy. This model will then be extended to $A_{x} B_{1-x} C_{y} D_{1-y}$ pseudoquaternaries. In the latter case, the theory which is based on the D.L.P. model of Stringfellow [8] takes into account a nonrandom atomic distribution on both sublattices and, so, will be reduced for the four pseudobinary III V solid solution cases to a quasi-chemical model. It will be shown that this model allows also to introduce clustering in $\mathrm{A}_{x} \mathrm{~B}_{y} \mathrm{C}_{1-x-y} \mathrm{D}$ (or $\mathrm{AB}_{x} \mathrm{C}_{y} \mathrm{D}_{1-x-y}$ ) pseudoternary alloys. Ultimately, the validity of this new III V solid solution model will be tested on equilibrium phase diagrams involving solid miscibility gap.

\section{Short-range order parameter (S.R.O.P.) ; calculation of the excess entropy of mixing, $\Delta^{\mathrm{xs}} S_{\mathrm{m}}^{\mathrm{s}}$.}

2.1 Pseudobinary alloys $\left(\mathrm{A}_{x} \mathrm{~B}_{1-x} \mathrm{C}\right.$ or $\left.\mathrm{AC}_{y} \mathrm{D}_{1-y}\right)$. 2.1.1 S.R.O.P. definition; its effect on the local structure. - In the metal sublattice of an $A_{x} B_{1-x} C$ alloy, in the zinc-blende structure, atoms $A$ and $B$ have twelve neighbours (Fig. 1). The AB pair number per mole, $\mathfrak{T}_{\mathrm{AB}}$, is related to the composition, $x$, and to the Avogadro number, $\mathcal{N}$, by the expression :

$$
\mathfrak{T}_{\mathrm{AB}}=12 \mathcal{N} x(1-x)\left(1-\alpha_{\mathrm{III}}\right) .
$$

Similar expressions will yield the AA and the BB

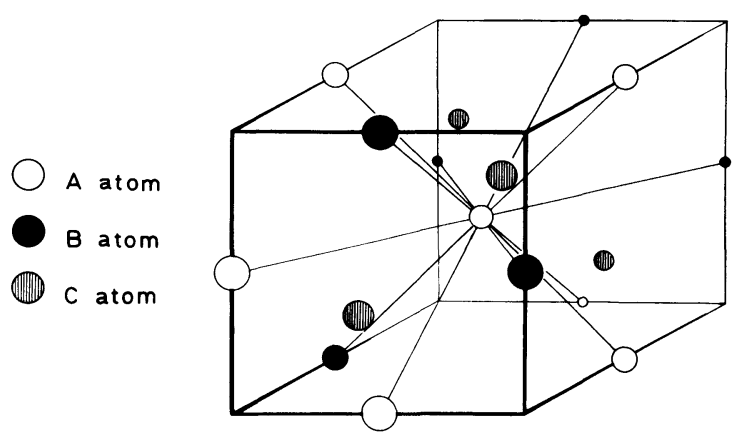

Fig. 1. $-\mathrm{A}_{x} \mathbf{B}_{1-x} \mathrm{C}$ : coordination polyhedron of an atom in the substituted sublattice (12 neighbours).

pair numbers, $\mathfrak{T}_{\mathrm{AA}}$ and $\mathfrak{T}_{\mathrm{BB}}$ :

$$
\begin{aligned}
& \mathfrak{J}_{\mathrm{AA}}=12 \mathcal{N}\left[x+\alpha_{\mathrm{III}}(1-x)\right] \\
& \mathfrak{T}_{\mathrm{BB}}=12 \mathcal{N}(1-x)\left[1-x+\alpha_{\mathrm{III}} x\right]
\end{aligned}
$$

In this set of relations analogous to the intermetallic alloy ones (Rudman and Averbach [9]), a short-range order parameter (S.R.O.P.), $\alpha_{\mathrm{III}}$, characterizing the clustering tendency of the A and B atoms in the twosite sublattice, is defined as follows :

$$
\alpha_{\text {III }}=-1-P_{\mathrm{BA}} / x \text {. }
$$

The limiting values of this Warren-Cowley type S.R.O.P. are 0 and $1, P$ re resen of finding an $\mathrm{A}$ atom next to a $\mathrm{B}$ atom. In the case of $\alpha_{\text {III }}=0$, atoms are randomly distributed and $\mathfrak{T}_{\mathrm{AB}}$ is maximum :

$$
\mathfrak{T}_{\mathrm{AB}}=12 \mathcal{N} x(1-x)
$$

But when $\alpha_{\text {III }}=1$, the clustering effect is maximum and $\mathfrak{T}_{\mathrm{AB}}=0$.

2.1.2 General thermodynamic properties of alloy with clustering. - In order to relate S.R.O.P. to thermodynamic functions of mixing, the method summarized by Swalin [10] has been followed. The Gibbs energy of mixing, $\Delta G_{\mathrm{m}}^{\mathrm{s}}$, referred to the $\mathrm{AC}$ and $\mathrm{AB}$ defined compounds, may be written in the following form :

$$
\Delta G_{\mathrm{m}}^{\mathrm{s}}=\mathfrak{T}_{\mathrm{AB}}[u+j(x)+g(T)]-T \Delta S^{\mathrm{c}}
$$

where $u$ is a constant, $j(x)$ a function of $x, g(T)$ a temperature depending term and $\Delta S^{\mathrm{c}}$ the configurational entropy. $\Delta S^{\mathrm{c}}$ is deduced from statistical calculation which uses the configuration number, $\omega$ :

$$
\Delta S^{\mathrm{c}}=k \log \omega
$$

( $k$ is the Boltzmann constant). Recalling that the entropy of mixing, $\Delta S_{\mathrm{m}}^{\mathrm{s}}$, is obtained by derivation of $\Delta G_{\mathrm{m}}^{\mathrm{s}}$ at constant pressure :

$$
\Delta S_{\mathrm{m}}^{\mathrm{s}}=\Delta S^{\mathrm{c}}-\frac{\partial}{\partial T}\left\{\mathfrak{T}_{\mathrm{AB}}[u+j(x)+g(T)]\right\}
$$


one deduces the corresponding expressions for the enthalpy of mixing :

$$
\Delta H_{\mathrm{m}}^{\mathrm{s}}=12 \mathcal{N}^{\prime} x(1-x)\left(1-\alpha_{\mathrm{III}}\right)[u+j(x)]
$$

and for the excess entropy of mixing :

$$
\begin{aligned}
\Delta^{\mathrm{xs}} S_{\mathrm{m}}^{\mathrm{s}} \simeq R \alpha_{\mathrm{III}}[x \log x+(1-x) \log (1-x)]- \\
-\frac{\hat{c}}{\hat{c} T}\left[12 \mathcal{N} x(1-x)\left(1-\alpha_{\mathrm{III}}\right) g(T)\right]
\end{aligned}
$$

( $R$ is the gas constant).

It can be noticed that $\Delta^{\mathrm{xs}} S_{\mathrm{m}}^{\mathrm{s}}$ may be either positive or negative as a consequence of the presence of the $g(T)$ term in (2.8). The quantity between brakets, $[u+j(x)+g(T)]$, introduced in $\Delta G_{\mathrm{m}}^{\mathrm{s}}$ and multiplied by the $12 \mathcal{N}$ factor, corresponds to the interaction parameter $\Omega$ in a regular model. In the quasi-chemical pair approximation of Guggenheim [11] :

$\mathfrak{T}_{\mathrm{AB}}=12 \mathcal{N} x(1-x)\left\{1-x(1-x)\left[\exp \frac{2 \Omega}{12 R T}-1\right]\right\}$.

For small deviation from ideality, i.e. if $\Omega / R T \lesssim 2.4$, the exponential term may be approximated as $1+\Omega / 6 R T$. Then, by comparison of (2.1a) and (2.9), the final expression for the S.R.O.P. is :

$$
\alpha_{\mathrm{III}} \simeq \frac{2 \mathcal{N} x(1-x)[u+j(x)+g(T)]}{R T} .
$$

In III-V solid solutions, $\Omega$ is often quasi-constant, implying from (2.10) that the S.R.O.P. is proportional to the inverse temperature and has a parabolic variation versus composition. This $T$ and $x$ behaviour is similar to that of intermetallic alloys (see for examples $\mathrm{Al}-\mathrm{Zn}$ and $\mathrm{Al}-\mathrm{Ag}$ (Rudman and Averbach, [9]) or $\mathrm{Cu}-$ Ni (Vrijen and Radelaar [12]). Of course, $\alpha_{\mathrm{III}}-$ and $\alpha_{\mathrm{V}}$ in the $\mathrm{AC}_{y} \mathrm{D}_{1-y}$ case - will all the more deviate from this double law as $\Omega$ is less constant and the solid solution gets further away from ideality.

On the other hand, the $[u+j(x)+g(T)]$ quantity is not immediately obtained from thermodynamic data. However, assuming that the $g(T)$ term versus $T$ is linear dependent :

$$
g(T)=g \cdot T
$$

the S.R.O.P. value is carried out, for given $x$ and $T$, through self consistent calculation (Swalin, [10]). So, for example, the thermodynamic analysis of the Ga-In-Sb system, made by Ansara et al. [13], leads for the $\mathrm{Ga}_{x} \mathrm{In}_{1-x} \mathrm{Sb}$ pseudobinary alloy to the set of data :

$$
\begin{aligned}
\Delta H_{\mathrm{m}}^{\mathrm{s}} & =2300 x(1-x) \text { cal.mole } \\
\Delta^{\mathrm{xs}} S_{\mathrm{m}}^{\mathrm{s}} & =0.4 x(1-x) \text { cal.mole } \\
& =\mathrm{K}^{-1}
\end{aligned}
$$

Assuming that this excess entropy is the consequence of a non-random distribution of the $\mathrm{Ga}$ and In atoms, (2.7), (2.8) and (2.10) may be used at different temperatures and compositions. Calculation yields positive values of $\alpha_{\mathrm{Ga}-\mathrm{In}}$ corresponding to clustering tendency of $\mathrm{Ga}$ and $\mathrm{In}$ atoms in $\mathrm{Ga}_{x} \mathrm{In}_{1-x} \mathrm{Sb}$. On the figure 2 is plotted the $\alpha_{\mathrm{Ga}-\mathrm{In}}$ variation versus $x$ at $800 \mathrm{~K}$. The set of the $\alpha_{\mathrm{Ga}-\text { In }}$ values follows the parabolic law :

$$
\alpha_{\mathbf{G a}-\mathrm{In}}=0.192 \times(1-x) .
$$

At $700 \mathrm{~K}$ and for $x=0.50$, calculation yields $\alpha_{\mathrm{Ga}-\mathrm{In}}=0.057$. The $\alpha_{\mathrm{Ga}-\mathrm{In}} \cdot T$ product remaining nearly constant $\left(\alpha_{\mathrm{Ga}-\mathrm{In}} \cdot 700=39.9 \mathrm{~K}, \alpha_{\mathrm{Ga}-\mathrm{In}} \cdot 800=\right.$ $38.4 \mathrm{~K}$ ) in the concerned temperature range, that means a nearly constant value for the $\mathcal{N}[u+j(x)+$ $g(T)]$ quantity in $(2.10): \mathcal{N}[u+j(x)+g(T)] \simeq$ $160 \mathrm{cal}^{\mathrm{mole}} \mathrm{m}^{-1}$.

2.1.3 The clustering tendency and the "delta lattice parameter " model. - Sometimes, experimental values of thermodynamic functions are unknown and the above semiempirical approach cannot be achieved. The "delta lattice parameter" (D.L.P.) model of Stringfellow [8], derived from the dielectric theory of Philips and Van Vechten [14-15], makes up for this inconvenient. In this model the enthalpy of formation of the III V alloy, $\Delta H^{\mathrm{s}}$, referred to the infinitely separated atoms, is related to the zincblende lattice parameter :

$$
\Delta H^{\mathrm{S}}=-K a^{-2.5} .
$$

In the above relation $K$ is a positive constant deduced from the $A_{x} B_{1-x} C$ and $A_{y} D_{1-y}$ III $V$ systems. Because of a very weak thermal dilatation of the lattice, the enthalpy may be considered as temperature independent. Thus, the excess entropy is reduced to the excess configurational entropy which is the first term

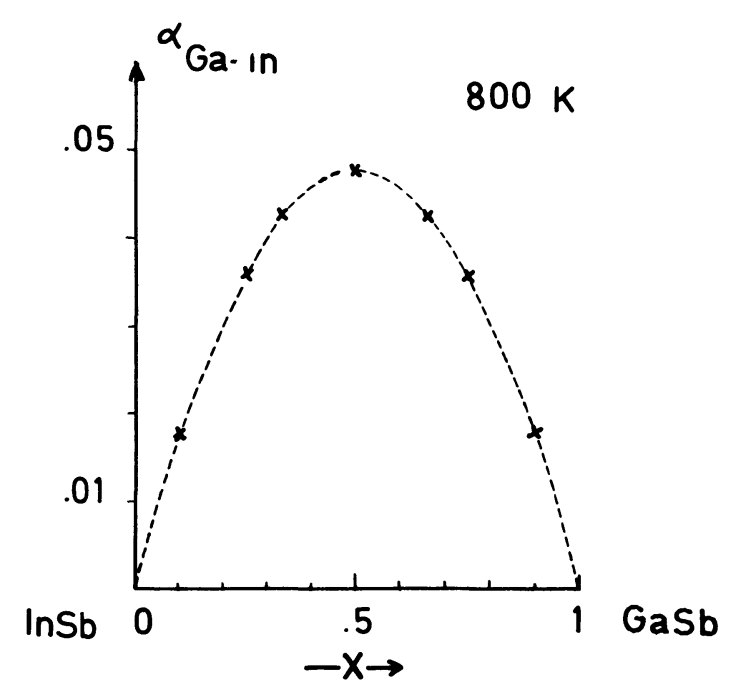

Fig. 2. $-\mathrm{Ga}_{x} \operatorname{In}_{1-x} \mathrm{Sb}: \alpha_{\mathrm{Ga}-\mathrm{In}}$ variation versus $x$ at $800 \mathrm{~K}$; dotted curve : $\alpha_{\mathrm{Ga}-\mathrm{In}}=0.192 \times(1-x)$; values deduced from the mixing functions of Ansara $([13], \times)$. 
of the right-hand side of (2.8) :

$\Delta^{\mathrm{xs}} S_{\mathrm{m}}^{\mathrm{s}} \simeq \Delta^{\mathrm{xs}} S^{\mathrm{c}}=R \alpha_{\mathrm{III}}[x \log x+(1-x) \log (1-x)]$.

The heat of mixing of the $\mathrm{A}_{x} \mathrm{~B}_{1-x} \mathrm{C}$ alloy, referred to the $\mathrm{AC}$ and $\mathrm{BC}$ pure compounds, may be expressed in terms of $a_{\mathrm{AC}}$ and $a_{\mathrm{BC}}$, lattice constants of $\mathrm{AC}$ and $\mathrm{BC}$ :

$\Delta H_{\mathrm{m}}^{\mathrm{s}}=-K\left[a^{-2.5}-x a_{\mathrm{AC}}^{-2.5}-(1-x) a_{\mathrm{BC}}^{-2.5}\right]$.

If the deviation from the ideality is not too high, (2.10) is of course available. Table I gives the $\alpha_{\mathrm{Ga}-\text { In }}$ values for the set of $\mathrm{Ga}_{x} \mathrm{In}_{1-x} \mathrm{X}$ alloys $(\mathrm{X}=\mathrm{P}, \mathrm{As}, \mathrm{Sb})$ with writing the S.R.O.P. under the reduced form :

$$
\alpha_{\mathrm{Ga}-\mathrm{In}}=\frac{4 \alpha_{\mathrm{m}} x(1-x) T_{\mathrm{m}}}{T}
$$

in which $\alpha_{m}$ is the S.R.O.P. value for $x=1 / 2$ at the arbitrary temperature, $T_{\mathrm{m}}$. On the same table the $\alpha_{\text {As }-P}$ values for the $\mathrm{GaAs}_{y} \mathrm{P}_{1-y}$ and $\operatorname{InAs} \mathrm{s}_{y} \mathrm{P}_{1-y}$ alloys are listed. The values of S.R.O.P. given by Yamazaki et al. [4] or deduced from Jones et al. [6] are also reported.

Equation (2.15) means that $\Delta H_{\mathrm{m}}^{\mathrm{s}}$ is symmetric about $x=1 / 2$ : this is not exactly the case in the D.L.P. model. Nevertheless, this model predicts a nearly symmetric miscibility gap (see section 3 ). In the extends more than the GaAs-rich one, the expression (2.15) is not available. If we assume that size effects play an important rôle in the substituted sublattice where $\mathrm{As}$ and $\mathrm{Sb}$ atoms have very different radii $\left(r_{\mathrm{As}}=1.225 \AA, \quad r_{\mathrm{Sb}}=1.405 \AA\right.$ in the Philips-Van Vechten scale [15]), an excess entropy of mixing term may be added to the configurational entropy, yielding a different expression of the total Gibbs function and possibility for $\mathrm{GaAs}_{y} \mathrm{Sb}_{1-y}$, to have an asymmetric miscibility gap.

The set of the S.R.O.P. values listed on table I

Table I. - S.R.O.P. in pseudobinary alloys (*).

\begin{tabular}{|l|cccc|}
\hline & $\alpha_{\mathrm{m}}$ & $\alpha(800 \mathrm{~K})$ & $4 \Delta(800 \mathrm{~K})\left(^{a}\right)$ & $\alpha\left(^{b}\right)$ \\
\cline { 2 - 5 } $\mathrm{Ga}_{x} \mathrm{In}_{1-x} \mathrm{P}$ & $0.08_{0}$ & $0.09_{8}$ & $0.09_{3}$ & 0.32 \\
$\mathrm{Ga}_{x} \mathrm{In}_{1-x} \mathrm{As}$ & $0.06_{2}$ & $0.07_{5}$ & $0.06_{6}$ & 0.31 \\
$\mathrm{Ga}_{x} \mathrm{In}_{1-x} \mathrm{Sb}$ & $0.04_{0}$ & $0.04_{9}$ & $0.03_{7}$ & 0.34 \\
$\mathrm{GaAs}_{y} \mathrm{P}_{1-y}$ & $0.01_{9}$ & $0.02_{3}$ & $0.03_{3}$ & 0.08 \\
$\mathrm{InAs}_{y} \mathrm{P}_{1-y}$ & $<0.02$ & & & 0.07 \\
\hline
\end{tabular}

$\left({ }^{a}\right)$ Jones, K. A., Porod, W. and Ferry, D. K., J. Phys. Chem. Solids 44 (1983) 107.

(b) Yamazaki, S., Kishi, M. and Katoda, T., Phys. Status Solidi (b) 113 (1982) 421.

$\left(^{*}\right)$ Value of the $\mathrm{K}$ « D.L.P. » constant : $11000 \mathrm{kcal} . \mathrm{mole}^{-1} . \AA^{2.5}$ [3]. allows several remarks :

- the evolution of $\alpha_{\mathrm{Ga}-\mathrm{In}}$ in the $\mathrm{Ga}_{\boldsymbol{x}} \mathrm{In}_{1-x} \mathrm{X}$ series agrees with the prediction of Foster and Woods [16] : the clustering tendency increases from the antimonide to the phosphide:

- $\mathrm{GaAs}_{y} \mathbf{P}_{1-y}$ and mainly $\operatorname{InAs} \mathrm{P}_{1-y}$, have a regular behaviour:

- for each pseudobinary the values are much smaller than Yamazaki et al. [4] ones and appear more realistic. At the same times they are very closed to Jones et al. [6] ones:

- for $\mathrm{Ga}_{x} \mathrm{In}_{1-x} \mathrm{Sb}$ the value is the same as the one obtained in the previous section, showing the consistency between both approaches.

2.2 Pseudoquaternary alloys $\left(\mathrm{A}_{x} \mathrm{~B}_{1-x} \mathrm{C}_{y} \mathrm{D}_{1-y}\right)$. The function of mixing of such alloys, referred to the $\mathrm{AC}, \mathrm{AD}, \mathrm{BC}$ and $\mathrm{BD}$ pure components, are not defined (Stringfellow [8], Jordan and Ilegems [17]) in the regular approximation. But with the addition of a quasi-chemical equilibrium relation, as in the theory of Onabe, the distribution of the AC, AD, BC and BD pairs is fixed [7] and allows calculation of such functions. The D.L.P. model however remains attractive, because considering atoms this approach allows to disconnect the two sublattices. Thus, the configurational entropy may be simply calculated by the generalization of (2.13) with two S.R.O.P., $\alpha_{\text {III }}$ and $\alpha_{\mathbf{v}}$.

So, if a non-random distribution occurs in an $\mathrm{A}_{x} \mathrm{~B}_{1-x} \mathrm{C}_{y} \mathrm{D}_{1-y}$ pseudo-quaternary solid solution, the written as follows : , will be

$$
\begin{aligned}
\Delta G^{\mathrm{s}}=-K a^{-2.5} & +R T\left[\left(1-\alpha_{\mathrm{III}}\right) \sum_{i=1}^{2} x_{i} \log x_{i}+\right. \\
& \left.+\left(1-\alpha_{\mathrm{V}}\right) \sum_{j=3}^{4} y_{j} \log y_{j}\right] .
\end{aligned}
$$

As the thermodynamic data of the pseudoquaternary must be consistent with those of the four limiting pseudobinaries $\left(\mathrm{A}_{x} \mathrm{~B}_{1-x} \mathrm{C}, \mathrm{A}_{x} \mathrm{~B}_{1-x} \mathrm{D}, \mathrm{AC}_{y} \mathrm{D}_{1-y}\right.$ and $\left.\mathrm{BC}_{y} \mathrm{D}_{1-y}\right)$, one deduces the four following conditions :

$$
\begin{aligned}
& \left.\alpha_{I I I}\right|_{y=1}=\alpha_{I I I A_{x} B_{1-x} C} \\
& \left.\alpha_{I I I}\right|_{y=0}=\alpha_{I I I A_{x} B_{1-x} D} \\
& \left.\alpha_{V}\right|_{x=1}=\alpha_{V_{A C} D_{1-y}} \\
& \left.\alpha_{V}\right|_{x=0}=\alpha_{V_{B_{y} D_{1-y}}} .
\end{aligned}
$$

The problem lies in the searching of the relationships between the pseudoquaternary and the corresponding pseudobinary S.R.O.P. For that purpose, the pair number may be calculated in each sublattice.

The total $\mathrm{AB}$ number, $\mathfrak{T}_{\mathrm{AB}}$, is the sum of the ACB triplet number involving $\mathrm{C}$ atom, $\mathfrak{C}_{\mathrm{ACB}}$, and the $\mathrm{ADB}$ triplet number involving $\mathrm{D}$ atom, $\mathcal{C}_{\mathrm{ADB}}$ :

$$
\mathfrak{T}_{\mathrm{AB}}=\mathfrak{C}_{\mathrm{ACB}}+\mathfrak{C}_{\mathrm{ADB}}
$$

$\mathcal{C}_{\text {ACB }}$ will be given by an expression similar to (2.1a) where the pair number involving a $\mathrm{C}$ atom is weighted 
by the probability to find a $\mathrm{C}$ atom on a $\mathrm{V}$ site, $P_{\mathrm{C}}$. A difficulty arises at this step in evaluating $P_{\mathrm{C}}$. As an approximation, $P_{\mathrm{C}}$ may be taken to the macroscopic probability, $y$. In the same manner, $\mathcal{C}_{\mathrm{ADB}}$ will be given by a relation where the probability to find a $\mathrm{D}$ atom on a $\mathrm{V}$ site, $P_{\mathrm{D}}$, is taken as $(1-y)$.

Thus :

$$
\begin{aligned}
& \mathfrak{T}_{\mathrm{AB}}=12 \mathcal{N}^{\prime} x(1-x)\left\{1-\left[y \alpha_{\mathrm{III} \mathbf{A}_{\mathbf{x}} \mathbf{B}_{1-x} \mathrm{C}}+\right.\right. \\
&\left.\left.+(1-y) \alpha_{\mathrm{III} \mathbf{A}_{x} \mathbf{B}_{1-x} \mathrm{D}}\right]\right\} .
\end{aligned}
$$

Rearranging the above expression, it is easy to recognize the pseudoquaternary S.R.O.P., $\alpha_{\text {III }}$ :

$$
\alpha_{\mathrm{III}}=y \alpha_{\mathrm{III} \mathbf{A}_{x} \mathbf{B}_{1-x} \mathrm{C}}+(1-y) \alpha_{\mathrm{III} \mathrm{A}_{x} \mathbf{B}_{1-x} \mathrm{D}} .
$$

The same type of relationship existing for $\alpha_{\mathbf{v}}$, it may be concluded that the S.R.O.P. of a sublattice varies linearly with the composition of the other sublattice and fills the four conditions (2.17). One may also see that in this particular model the non-random atomic distribution in a pseudoquaternary occurs as a consequence of the quasi-chemical nature of the bonds in the four limiting pseudobinaries. The linear variation of $\alpha_{\mathrm{III}}$ and $\alpha_{\mathrm{V}}$ is similar to that of the lattice potential in the virtual crystal approximation (V.C.A.) where the band structure of a semiconductor alloy is calculated by assuming a local distribution similar to the macroscopic one [18].

2.3 PSEUdoternary alloys $\left(\mathrm{A}_{x} \mathrm{~B}_{y} \mathrm{C}_{1-x-y} \mathrm{D}\right.$ OR $\left.\mathrm{AB}_{x} \mathrm{C}_{y} \mathrm{D}_{1-x-y}\right)$. - An apparent lack of the presented model lies for pseudoternary alloys where mixing of three different atoms implies three sites, whereas the Warren-Cowley S.R.O.P. are defined for two sites sublattices by (2.2). In fact, it may be remembered that an excess function of mixing may always be taken as the sum of all corresponding binary functions (see for example Ansara [19]), corrected eventually by an additional term taking into account ternary interactions. As a consequence, the excess configurational entropy of a $\mathrm{A}_{x} \mathrm{~B}_{y} \mathrm{C}_{1-x-y} \mathrm{D}$ pseudoternary alloy may be written as follows :

$$
\begin{aligned}
\Delta^{\mathrm{xs}} S^{\mathrm{c}}=\Delta^{\mathrm{xs}} & S_{(\mathrm{A}, \mathrm{B}) \mathrm{D}}^{\mathrm{c}}+\Delta^{\mathrm{xs}} S_{(\mathrm{A}, \mathrm{C}) \mathrm{D}}^{\mathrm{c}}+ \\
& +\Delta^{\mathrm{xs}} S_{(\mathrm{B}, \mathrm{C}) \mathrm{D}}^{\mathrm{c}}+x y(1-x-y) \Lambda .
\end{aligned}
$$

In the above expression, one may recognize the three pseudobinary terms, $\Delta^{\mathrm{xs}} S_{(\mathrm{II}, \mathrm{III}) \mathrm{V}}^{\mathrm{c}}$, and the additional term with its constant $\Lambda$.

The total entropy of configuration, $\Delta S^{\mathrm{c}}$, takes the final form :

$$
\begin{aligned}
\Delta S^{\mathbf{c}}=R\left\{\left[1-\left(\alpha_{\mathrm{A}-\mathrm{B}}+\alpha_{\mathrm{A}-\mathrm{C}}\right)\right] x \log x+\left[1-\left(\alpha_{\mathrm{A}-\mathrm{B}}+\alpha_{\mathrm{B}-\mathrm{C}}\right)\right] y \log y+\right. \\
\left.+\left[1-\left(\alpha_{\mathrm{A}-\mathrm{C}}+\alpha_{\mathrm{B}-\mathrm{C}}\right)\right](1-x-y) \log (1-x-y)\right\}+x y(1-x-y) \Lambda .
\end{aligned}
$$

It is easy to see that the above expression reduces to the pseudobinary ones when $x, y$ or $(1-x-y)$ equal 0.

As for pseudoquaternary, the non-random atomic distribution in a pseudoternary alloy is related to the quasi-chemical nature of the bonds in the limiting pseudobinaries.

\section{Calculation of III V miscibility gaps.}

3. 1 A miscibility gap corresponds to a two-phase field of composition ${ }^{\mathrm{I}} x,{ }^{\mathrm{I}} y$ and ${ }^{\mathrm{II}} x$, ${ }^{\mathrm{II}} y$. The equilibrium conditions may be completely determined by searching the minimum of the total Gibbs energy, $\Delta G^{\mathbf{S}}$ :

$$
\Delta G^{\mathrm{s}}=f \cdot{ }^{\mathrm{I}} \Delta G^{\mathrm{S}}+(1-f) .{ }^{\mathrm{II}} \Delta G^{\mathrm{S}}
$$

the total composition $\left(x^{0}, y^{0}\right), P$ and $T$ remaining constant. In the above expression the fraction $f$ of the ${ }^{\mathrm{I}} S$ phase (Gibbs energy ${ }^{\mathrm{I}} \Delta G^{\mathrm{S}}$ ) is given by the lever rule. whereas " $\Delta G$ is the Gibbs energy of the second phase, ${ }^{\text {II }} S$.

If a stabilization effect by the epitaxial substrate is taken into account, an excess term may be added to the Gibbs energy as a consequence of elastic strain $[1-3]$ :
$\Delta^{\mathrm{xs}} G^{\mathrm{S}}=3.6 \times 10^{-12}\left(\frac{E a^{4}}{1-v}\right)_{\mathrm{III} \mathrm{V}_{\mathrm{ref}}}\left(\frac{a-a_{\mathrm{sub}}}{a_{\mathrm{sub}}}\right)^{2} \frac{1}{a}$

(kcal.mole ${ }^{-1}$ units).

This relation which was earlier established [3] is only available in the pure elastic strain case $\left(\left|a-a_{\text {sub }}\right| / a<10^{-3}\right) ; E$ is the Young's modulus and $v$ the Poisson's ratio of one of the limiting III V compounds taken as a reference; the composite elastic constant, $E /(1-v)$, which depends on the substrate orientation (Brantley [20]), is expressed in dynes. $\mathrm{cm}^{-2}$ units; $a_{\text {sub }}$ is the lattice parameter of the substrate.

The values of the parameters used for the calculation, are listed on table II ; in the evaluation of $E /(1-v)$ which is function of the elastic compliance, $s_{i j}$, GaP (or GaAs) is taken as reference, according to the studied multicomponent system.

The $\Delta G^{\mathrm{s}}$ minimization is achieved without any differentiation by a " simplex » type method (Ansara [19], Nelder and Mead [21]). The miscibility gap has been determined by this method for the following alloys where solid instability occurs :

- $\mathrm{Ga}_{x} \operatorname{In}_{1-x} \mathrm{P}$ (Fig. 3)

- $\mathrm{Ga}_{x} \operatorname{In}_{1-x} \mathrm{As}_{y} \mathbf{P}_{1-y}$ (Figs. 4 and 5). 
Table II. - Constant values used in calculations.

\begin{tabular}{|l|ccccc|}
\hline & $a / \AA \AA\left(^{a}\right)$ & $\beta / \AA \mathrm{K}^{-1}$ & $s_{11}\left({ }^{d}\right)$ & $s_{12}\left({ }^{d}\right)$ & $s_{44}\left({ }^{d}\right)$ \\
\cline { 2 - 6 } $\mathrm{GaP}$ & 5.4512 & $5.81 \times 10^{-6}\left({ }^{b}\right)$ & 0.967 & -0.295 & 1.420 \\
$\mathrm{GaAs}$ & 5.6532 & $6.63 \times 10^{-6}\left(^{b}\right)$ & 1.173 & -0.366 & 1.684 \\
$\mathrm{GaSb}$ & 6.0959 & & & & \\
$\mathrm{InP}$ & 5.8687 & $4.75 \times 10^{-6}\left({ }^{b}\right)$ & & & \\
InAs & 6.0584 & $5.19 \times 10^{-6}\left({ }^{c}\right)$ & & & \\
InSb & 6.4794 & & & & \\
\hline
\end{tabular}

$\left({ }^{a}\right)$ Panish, M. B. and Ilegems, M., Prog. Solid State Chem. (Reiss and McCaldin, Pergamon Press, Oxford) vol. 7, 1972, p. 39.

$\left({ }^{b}\right)$ Kudman, I. and Paff, R. J., J. Appl. Phys. 43 (1972) 3760.

(c) Glazov, V. M. and Chizhevskaya, V. M., Sov. Phys. Solid State 6 (1964) 1322.

$\left({ }^{d}\right)$ Elastic compliances in $10^{-12} \mathrm{~cm}^{2}$.dyne ${ }^{-1}$ given in reference [20].

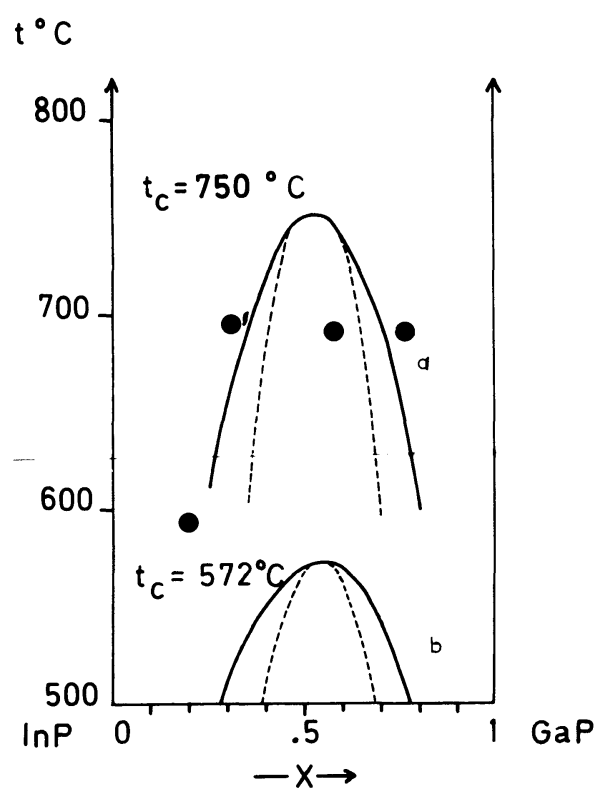

Fig. 3. $-\mathrm{Ga}_{x} \operatorname{In}_{1-x} \mathrm{P}$ : calculated miscibility gap (-) and spinodal curve (--.) with $\alpha_{\mathrm{Ga}-\mathrm{In}}=0.320 x(1-x)$ 973/T (a) and $\alpha_{\mathrm{Ga}-\mathrm{In}}=0$ (b); Mabbitt points ([22],

For the pseudobinary systems, the spinodal curve which delimits the metastable extension of the miscibility gap is also reported. These dotted lines are obtained by solving the classical spinodal equation :

$$
\left|\begin{array}{ll}
\partial^{2} \Delta G^{\mathrm{s}} / \partial x^{2} & \partial^{2} \Delta G^{\mathrm{s}} / \partial x \partial y \\
\partial^{2} \Delta G^{\mathrm{s}} / \partial x \partial y & \partial^{2} \Delta G^{\mathrm{s}} / \partial y^{2}
\end{array}\right|=0
$$

where $T$ and $P$ remain constant.

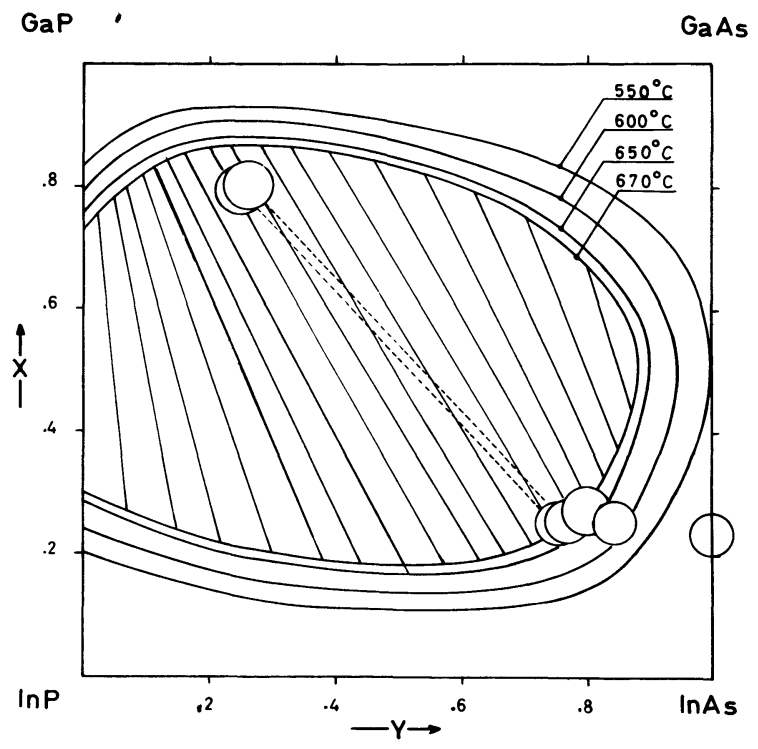

Fig. 4. $-\mathrm{Ga}_{x} \mathrm{In}_{1-x} \mathrm{As}_{y} \mathrm{P}_{1-y}$ : calculated solidus isotherms $(\longrightarrow)$ with tie-lines; L.P.E. points of Quillec et al. $(\mathrm{GaP}$ substrate [2], O) with experimental tie-lines (----).

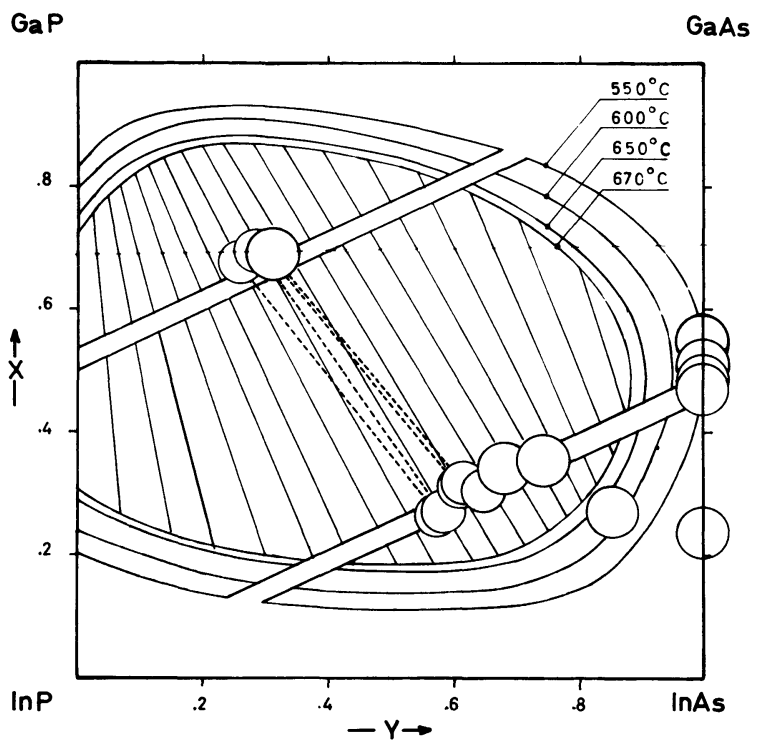

Fig. 5. - $\mathrm{Ga}_{x} \operatorname{In}_{1-x} A s_{y} \mathrm{P}_{1-y} / \mathrm{GaAs}$ or InP : calculated solidus isotherms $(\longrightarrow)$ with tie-lines; L.P.E. points of Quillec et al. (InP substrate [2], O) with experimental tielines (----).

The importance of the introduction of S.R.O.P. for the shape and the locus of miscibility gap may be seen in the particular case of pseudobinaries. Using the (2.13) and (2.14) forms for mixing functions and the reduced form for $\alpha$, the solution of equation (3.3) $T_{(\alpha)}$ is :

$T_{(\alpha)}=T_{(0)}+4 \alpha_{m} T_{m} x(1-x)\left\{1+2\left[(1-2 x) \log \frac{x}{1-x}-x \log x-(1-x) \log (1-x)\right]\right\}$ 
where $T_{(0)}$ is the solution of the spinodal equation for an random alloy :

$T_{(0)}=8.75 K x(1-x) x a^{-4.5}\left(a_{\mathrm{AC}}-a_{\mathrm{BC}}\right)^{2} / R$.

Generally, the maximum of the spinodal curve occurs very near $x=1 / 2$, which leads to :

$$
T_{(\alpha)} \simeq T_{(0)}+\alpha_{m} T_{m}(1+2 \log 2) .
$$

It means that clustering tendency yields an increasing of critical temperatures : for $\alpha_{\mathrm{m}}=0.10$ and $T_{\mathrm{m}}=973 \mathrm{~K}$, one finds an increasing of $232 \mathrm{~K}$.

3. $2 \mathrm{Ga}_{x} \mathrm{In}_{1-x} \mathrm{P}$ MISCIBILITY GAP. - For the random alloy instability occurs below $572{ }^{\circ} \mathrm{C}$, whereas with a clustering tendency $\left(\alpha_{\mathrm{m}}=0.08\right)$ it occurs below $750^{\circ} \mathrm{C}$. In such a position the miscibility gap explains Mabbitt's results [22] (experimental points $\bullet$ of Fig. 3) : this author showed it was impossible to grow alloys by L.P.E. by using GaP substrate, below $690^{\circ} \mathrm{C}$, in the composition range $0.35-0.55$.

As previously reported [3], the critical temperature at which the demixion occurs is found to be $693^{\circ} \mathrm{C}$, if $\alpha_{\mathrm{Ga}-\mathrm{In}}$ remains constant versus $T$ and $x$ and equal to the Brühl's value $\left(\alpha_{G-I n}=0.13,[5]\right)$. This approximation cannot be maintained in view of (2.10) and (2.15). On the other hand the experimental value of these authors was obtained by study of polycristalline ingots which were grown at $1040^{\circ} \mathrm{C}$ and cooled to room temperature without quenching. Therefore, more informations on $\alpha_{G a-I n}$ are needed for a better understanding of $\mathrm{Ga}_{x} \mathrm{In}_{1-x} \mathrm{P}$, given by direct physical studies, such as diffuse $\mathbf{X}$. Ray scattering, on alloys in thermal equilibrium.

3. $3 \mathrm{Ga}_{x} \operatorname{In}_{1-x} \mathrm{As}_{y} \mathbf{P}_{1-y^{*}}$ - The figure 4 shows the $550^{\circ} \mathrm{C}, 600^{\circ} \mathrm{C}, 650^{\circ} \mathrm{C}$ and $670{ }^{\circ} \mathrm{C}$ isothermal sections of the miscibility gap. For figure 5 , the influence of a $\langle 100\rangle$ oriented substrate, i.e. GaAs or InP, has been added, yielding a "channel " of stability across the gap : its width corresponds to the maximum latticemismatch introduced in the calculation $\left(\Delta a / a \lesssim 10^{-3}\right)$. On both figures, tie-lines joining the compositions of the two-phase field, are represented. Experimental points of Quillec et al. [2] are quoted as large circles. By comparison with these experiments or earlier calculations $[1,23]$ one can see :

- the solid calculated tie-lines, excepted the edge ones, are rotated to lie nearly along to the GaP-InAs diagonal of the composition square. The same result has been obtained in the classical regular D.L.P. model by Stringfellow [23]. It means that the clustering tendency goes towards formation of $\mathrm{GaP}$ and InAsrich clusters. The orientation of the experimental tieline disagrees with the calculated one for As-rich alloys $(y \gtrsim 0.75)$ in the case of L.P.E. on InP substrate (Fig. 5);

- no miscibility gap is predicted at $600^{\circ} \mathrm{C}$ in the
GaAs-InAs pseudobinary, whereas in experiments (Fig. 5) a two-phase field occurs [2];

- from a thermodynamic point of view, peritecticlike decomposition is possible : the phase rule however implies that all the properties of this quaternary system are known if for example two of the mole fractions of the melt are fixed. So, the experimental conditions of [2] $\left(x_{\mathrm{Ga}}^{1}=0.0107, x_{\mathrm{As}}^{1}=0.048\right)$ allow only one tie-line. Because the disagreements occur for growths on InP substrate, it may be remembered that thermodynamic models do not generally take into account interfacial phenomena, such as those occurring between InP and Ga-In-As (or Ga-In-As-P) melts [24]. That means, in this case, that thermodynamics cannot completely explain all the experiments of this example,

- Figure 5 shows that growth inside the unstable region is possible, in agreement with previous works $[2,25]$ for lattice-matched solids. In fact, the stabilization by the substrate is not perfect and compositional fluctuations occur as recently shown by Quillec et al. [26].

- The critical temperature given by the present model is $883^{\circ} \mathrm{C}$, whereas in the regular approximation a slightly lower value is obtained $\left(808^{\circ} \mathrm{C}\right.$. Stringfellow [23]). These two values are far from the one deduced from the quasi-chemical treatment of Onabe : this author founds the limiting value 1 for GaP and InAs activities at $400{ }^{\circ} \mathrm{C}$ for $\mathrm{Ga}_{0.50} \mathrm{In}_{0.50} \mathrm{As}_{0.50} \mathrm{P}_{0.50}$ [7]. In this case, in contradiction with experiments, a pseudoquaternary would be less unstable than the limiting pseudobinaries ([23], [27]).

\section{Conclusions.}

A new thermodynamic model describing both pseudobinary, pseudoternary and pseudoquaternary III V alloys has been established. Connected to the D.L.P. model, this theory takes into account a non-random distribution of the atoms in each substituted sublattice by calculating positive short-range order parameter (S.R.O.P.) depending on temperature and composition. In such a way, the clustering tendency decreases monotonically in the $\mathrm{Ga}_{x} \operatorname{In}_{1-x} \mathrm{X}$ set $(\mathrm{X}=\mathrm{P}, \mathrm{As}, \mathrm{Sb})$ from the phosphide to the antimonide, whereas $\mathrm{GaAs}_{\boldsymbol{y}} \mathbf{P}_{1-y}$ have quite random As-P distribution.

It has been also shown that, in pseudoquaternary alloys, the S.R.O.P. of a sublattice varies linearly with the composition of the other sublattice. The presented model allows also to express the entropy of mixing of a pseudoternary solid solution in taking into account the clustering concept of three different atoms on the same sublattice.

The miscibility gaps have been calculated by minimizing the total Gibbs energy of a pseudobinary or pseudoquaternary two-phase system. Good agreement with earlier experiments for $\mathrm{Ga}_{x} \mathrm{In}_{1-x}$ and $\mathrm{Ga}_{x} \operatorname{In}_{1-x} A s_{y} \mathrm{P}_{1-y}$ is found, whereas the model does 
not explain the asymmetrical shape of the miscibility gap of $\mathrm{GaAs}_{y} \mathrm{Sb}_{1-y}$ if the excess entropy of mixing reduces only to a configurational term.

Evidence occurs that further experimental investi- gations of clustering, such as diffuse $\mathrm{X}$. Ray scattering, are needed in order to obtain informations on the S.R.O.P. in III V alloys and related problems : band gap calculations, phonon spectra

\section{References}

[1] De Cremoux, B., Hirtz, P. and Ricciardi, J., GaAs and Related Compounds (Thim, Inst. of Phys., London) 1980, p. 115.

[2] Quillec, M., Daguet, C., Benchimol, J. L. and Launois, H., Appl. Phys. Lett. 40 (1982) 32.

[3] Marbeuf, A. and Guillaume, J. C., Colloque International sur les Relations entre les Conditions de Croissance Epitaxiale et les Propriétés des Couches Epitaxiales Semiconductrices (Editions de Physique) J. Physique Colloq. 43 (1982) C5-47.

[4] Yamazaki, S., Kishi, M. and Katoda, T., Phys. Status Solidi (b) 113 (1982) 421.

[5] BRÜHL, H. G., HILdISCH, L., MoRvinsKI, H., SChMidT, W. and Schubert, E., Phys. Status Solidi (a) 39 (1977) 133.

[6] Jones, K. A., Porod, W. and Ferry, D. K., J. Phys. Chem. Solids 44 (1983) 107.

[7] Onabe, K., J. Phys. Chem. Solids 43 (1982) 1071.

[8] Stringfellow, G. B., J. Cryst. Growth, 27 (1974) 21.

[9] Rudman, P. S. and Averbach, B. L., Acta Metall. 2 (1954) 576.

[10] Swalin, R. A., Thermodynamics of Solids (Wiley, New-York) 1962, p. 148.

[11] GuggenheIM, Mixtures (Oxford Press, London) 1952.

[12] Vrijen, J. and RadelaAr, S., Phys. Rev. B 17 (1978) 409.
[13] Ansara, I., Gambino, M. and Bros, J. P., J. Crystal. Growth 32 (1976) 101.

[14] Philips, J. C. and Van Vechten, J. A., Phys. Rev. B 2 (1970) 2147.

[15] Philips, J. C. and Van Vechten, J. A., Phys. Rev. B 2 (1970) 2160.

[16] Foster, L. M. and Woods, J. F., J. Electrochem. Soc. 118 (1971) 1175.

[17] Jordan, A. S. and Ilegems, M., J. Phys. Chem. Solids 36 (1975) 329.

[18] Van Vechten, J. A. and Bergstresser, T. K., Phys. Rev. B 1 (1970) 3351.

[19] Ansara, I., Int. Met. Rev. 1 (1978) 20.

[20] Brantley, W. A., J. Appl. Phys. 44 (1973) 534.

[21] Nelder, J. A. and MeAd, R., Comp. J. 7 (1965) 308.

[22] Mabbitt, A. W., J. Mat. Sci. 5 (1970) 1043.

[23] Stringfellow, G. B., J. Cryst. Growth 58 (1982) 194.

[24] Henoc, P., Izrael, A., Quillec, M. and Launois, H., Rapport annuel CNET-PARIS B (Division P.M.S.) 1981.

[25] HsIEH, J. J., I.E.E. J. Quantum Electron. 17 (1981) 118

[26] Henoc, P., Izrael, A., Quillec, M. and Launois, H., Appl. Phys. Lett. 40 (1982) 963.

[27] Onabe, K., Japan J. Appl. Phys. 21 (1982) L-323. 